\title{
Display of heterologous proteins on the surface of microorganisms: From the screening of combinatorial libraries to live recombinant vaccines
}

\author{
George Georgiou*, Christos Stathopoulos', Patrick S. Daugherty, Amiya R. Nayak', \\ Brent L. Iverson', and Roy Curtiss III'
}

Department of Chemical Engineering, University of Texas, Austin, TX 78712. 'Department of Biology, Washington University, St. Louis, MO 63130. ${ }^{2}$ Department of Chemistry and Biochemistry, University of Texas, Austin, TX 78712. ${ }^{*}$ Corresponding author (e-mail gg@che.utexas.edu).

Received 9 September 1996; accepted 1 December 1996

\begin{abstract}
In recent years there has been considerable progress towards the development of expression systems for the display of heterologous polypeptides and, to a lesser extent, oligosaccharides on the surface of bacteria or yeast. The availability of protein display vectors has in turn provided the impetus for a range of exciting technologies. Polypeptide libraries can be displayed in bacteria and screened by cell sorting techniques, thus simplifying the isolation of proteins with high affinity for ligands. Expression of antigens on the surface of nonvirulent microorganisms is an attractive approach to the development of high-efficacy recombinant live vaccines. Finally, cells displaying protein receptors or antibodies are of use for analytical applications and bioseparations.
\end{abstract}

Keywords: protein display, library screening, live bacterial vaccines

The display of heterologous proteins on the surface of the plasma membrane of eukaryotic cells can be readily accomplished using a phosphatidylinositol-glycan (PI-G) anchor. Fusion proteins linked to a PI-G anchor have been used extensively in biotechnology, mostly for the expression of heterologous proteins on the cell surface $^{1}$. Unfortunately, there is no microbial equivalent of the PI-G anchor for the facile display of heterologous proteins in prokaryotic or lower eukaryotic cells. However, in recent years there has been great progress in the development of expression systems for the display of proteins in Escherichia coli, Gram-positive bacteria, and yeast. The ability to display heterologous molecules on the surface of microorganisms is generating intriguing opportunities for a number of applications. They include, to name a few, recombinant bacterial vaccines, systems for the screening of polypeptide libraries, whole cell adsorbents, recombinant whole cell biocatalysts and cell-based solid phase reagents for diagnostics ${ }^{2,3}$.

Expression systems. Several fusion protein strategies for the display of relatively short peptides on the surface of Gram-negative bacteria have been described (Table 1). Short peptides of less than 60 amino acid residues can be displayed on the cell surface when fused into surface exposed loops of outer membrane proteins (OMPs) from enteric bacteria ${ }^{4-9}$. Hofnung and coworkers were the first to demonstrate that peptides inserted within permissive sites of the E. coli outer membrane protein LamB are displayed on the cell surface, accessible to antibodies in the extracellular fluid and have thus been exploited extensively for practical applications $s^{4,10-12}$ (P. Klebba, private communication). However, it was quickly realized that the insertion of peptides longer than 60 amino acids perturbs the overall conformation and assembly of the carrier, interfering with the localization of the fusion proteins ${ }^{4-6}$. Moreover, the positioning and length of the peptide insert plays a critical role in the efficient surface display and recognition of the inserted epitope $e^{7-9}$.
Extracellular proteinaceous appendages like pili and flagella have also been used successfully for the display of heterologous peptides. McCoy and colleagues ${ }^{13}$ developed the FLITRX system, an ingenious $E$. coli display vector based on FliC, the major structural component of the $E$. coli flagellum. First, the small redox protein thioredoxin was introduced into a dispensable region of FliC and was shown to become surface exposed. Then, peptides were inserted within the thioredoxin domain in the FliC fusion. Thioredoxin represents a highly versatile scaffold that allows peptide inserts to assume a conformation compatible with binding to other protein $s^{14}$. In a different approach, Fiers and colleagues expressed the immunoglobulin G-binding domain of protein A of Staphylococcus aureus on the surface of E. coli using PapA, the major subunit of the Pap pilus ${ }^{15}$. Other groups have used flagellum or pilus subunits to develop expression systems for the surface presentation of antigenic/immunogenic epitopes derived from pathogens, suitable for the development of live recombinant vaccines ${ }^{16-18}$.

For reasons that are not fully understood, subunits of cellular appendages and outer membrane porins are not suitable for the surface display of large polypeptides. To overcome this problem it has been necessary to use surface display carrier proteins that are exported via more specialized mechanisms ${ }^{19}$. For example, the targeting of many lipoproteins from Gram-negative bacteria onto the outer membrane is determined only by the presence of a short $\mathrm{N}$-terminal sequence. Because of this property, several lipoproteins have been tested as potential carriers for surface display ${ }^{20-23}$. Unfortunately, lipoprotein fusions have been found to be either detrimental to the integrity of the cell envelope, causing extensive cell lysis, or to be tethered to the interior face of the outer membrane, in which case they are not exposed to the extracellular fluid $^{21,23}$. These limitations have been addressed by constructing an Lpp-OmpA hybrid display vehicle consisting of the $\mathrm{N}$-terminal 
outer membrane localization signal from the major lipoprotein (Lpp) fused to a domain from the outer membrane protein $\mathrm{OmpA}^{24}$. OmpA mediates the display of passenger proteins fused to the C-terminal of the Lpp-OmpA hybrid. Lpp-OmpA fusions have been used to successfully display on the surface of $E$. coli several proteins varying in size between 20 and $54 \mathrm{kDa}^{25}$. Among the proteins that have been tested thus far only the dimeric bacterial enzyme alkaline phosphatase (PhoA) could not be displayed on the cell surface ${ }^{25}$.

The IgA proteases of Neisseria gonorrhoeae and Hemophilus influenzae use a variation of the most common, Type II secretion pathway ${ }^{19}$, to achieve extracellular export independent of any other gene products ${ }^{26}$. Specifically, the C-terminal domain of the IgA protease forms a channel in the outer membrane that mediates the export of the $\mathrm{N}$-terminal domain across the membrane which in turn becomes transiently displayed on the external surface of the bacteria. This export mechanism is used by a number of extracellular proteins from pathogenic bacteria ${ }^{26-30}$. Replacement of the native $\mathrm{N}$-terminal domain of IgA protease or VirG with the cholera toxin B subunit or the periplasmic E. coli protein MalE, respectively, resulted in the surface presentation of the passenger polypeptides ${ }^{28,31}$.

Unlike the IgA protease, the lipoprotein pullulanase (PulA) of Klebsiella pneumoniae, which is also exported via a type II secretion mechanism, requires 14 genes for its translocation across the outer membrane $e^{19}$. Pugsley and coworkers have shown that the lipoprotein pullulanase (PulA) can facilitate translocation of the periplasmic enzyme $\beta$-lactamase across the outer membrane. However, pullulanase hybrids remain only temporarily attached to the bacterial surface and are subsequently released into the medium ${ }^{32}$. Although the lack of permanent association with the cell wall is not detrimental for vaccine development, it is a serious limitation in other applications such as library screening.

Expression systems for the display of proteins in Gram-positive bacteria have also been developed ${ }^{33}$. Uhlen and colleagues used fusions to the cell-wall bound, X-domain of protein A, for the display of foreign peptides up to 88 amino acids long to the surface of Staphylococcus strains $\mathrm{s}^{34,35}$. In other studies, the fibrillar M6 protein of Streptococcus pyogenes was employed as a carrier for antigen delivery in Streptococcus cells ${ }^{36}$.

Protein display applications has also spurred the development of suitable expression systems for yeast cells. Surface display expression systems for yeast have relied primarily on the fusion of passenger proteins to agglutinin, a protein involved in cell adhesion $^{37-40}$. The $A G \alpha 1$ agglutinin is tightly bound to the cell wall through its C-terminus. N-terminal fusions to the cell wall domain of AGA1 are stably anchored on the cell surface. This system has been used for the surface expression of a variety of enzymes and binding proteins $s^{39}$. Mating-type a cells use the two subunit agglutinin a for cell adhesion. Recently the second subunit of agglutinin a (Aga2p) was used as a vehicle for the surface display of antibodies and peptides ${ }^{40}$. In this case, the passenger polypeptide is fused to the C-terminus of AGA2 which, in turn, is linked to the AGA1 via disulfide bonds.

Clearly, the number of expression systems for protein and peptide display has expanded rapidly in the last few years. Despite significant progress, many challenges remain. First, the surface display of multisubunit proteins has not yet been demonstrated. Second, the display of heterologous proteins is usually accompanied by alterations on the cell surface that result in growth defects $^{41}$. Finally, there is relatively little available information on the effects of native surface molecules on the function and accessibility of heterologous proteins. Factors such as susceptibility to surface proteases, conformational constraints imposed by the attachment to the carrier protein or steric effects due to the presence of native surface molecules can affect the function and utility of surface displayed polypeptides ${ }^{4,13,26,37}$.

In addition to the display of proteins, there are instances where it is desirable to engineer the exposure of other macromolecules, most notably oligosaccharides, on the surface of microorganisms. For example, bacterial surface layer glycoproteins have been used as carriers for the display of heterologous oligosaccharides ${ }^{42}$. Bacillus bacteria coated with oligosaccharides from Streptococcus pneumoniae linked to S-layer glycoproteins have been tested for vaccination and immunotherapy purposes ${ }^{43}$. In other studies, Goldberg et al..$^{4}$ cloned a 26-kb DNA fragment encoding the locus of $\mathrm{O}$-antigen synthesis from a Pseudomonas aeruginosa strain into E. coli. The heterologous $\mathrm{O}$-antigen was incorporated into a core lipopolysaccharide and rabbits immunized with these bacteria produced antibodies against the $P$. aeruginosa $\mathrm{O}$-antigen.

Display and screening of polypeptide libraries. One of the most important, and vigorously pursued, applications of cell surface display is the screening of polypeptide libraries for the isolation of high-affinity ligands to target molecules. Presently, there are many routes, biological or synthetic, to construct libraries of small molecules. However, protein libraries can only be made biosynthetically. The most widely used technology for the screening of protein libraries uses display on filamentous bacteriophages ${ }^{45,46}$. Phage display has been used with considerable success in numerous applications such as the isolation of hormone mutants exhibiting improved receptor binding, epitope mapping, the isolation of enzyme inhibitors and receptor antagonists, the determination of protease sequence specificity, and, perhaps most importantly, antibody engineering ${ }^{47-55}$.

Cell surface displayed libraries (CSDLs) are emerging as a screening methodology that represents a powerful complement to phage display. Libraries of short peptides inserted within surface exposed sites of E. coli, LamB and FliC, can be successfully screened by sequential binding and elution ${ }^{10,13}$. These studies demonstrated that the isolation of high affinity peptides from cell surface displayed libraries is feasible, despite the multivalent binding of the bacteria to the immobilized ligands and the relatively large size of the cells. However, the power of CSDLs lies in the ability to use fluorescence activated cell sorting (FACS) for high throughput screening. FACS cannot be used with phage displayed libraries because of the small size of bacteriophages.

Cell sorting provides two distinct advantages: (1) high enrichment ratios of positive clones, defined as (positive clones/total clones $\left.)_{\text {post-screen }} /(\text { positive clones/total clones })_{\text {pre-screen }}\right)$ and (2) the ability to discriminate directly between binders of different affinity and specificity. E. coli displaying a single chain Fv antibody ( $\mathrm{scFv}$ ) fused to Lpp-OmpA can be readily enriched from a $10^{5}$-fold excess of background bacteria in two rounds ${ }^{56}$. An enrichment factor of over 300:1 per round was obtained in these early studies. With more recent advances in methodology, it is possible to obtain enrichment factors as high as 10,000:1 per round even with a low-end flow cytometer (unpublished observation). Enrichment factors greater than $10^{6}: 1$ per step can be obtained with state of the art flow sorting instrumentation ${ }^{56}$. With the introduction of surface display systems for Gram-positive bacteria and yeast $\mathrm{t}^{33,34,39,40}$ the same screening format, i.e. FACS, may be employed to screen CSDLs in different microorganisms. Using an appropriate shuttle vector it should be possible to screen a single library in different microorganisms, thus taking advantage of the distinct expression capabilities of different microbial hosts to expand the effective sequence space that can be sampled.

The screening of CSDLs by FACS begins with the incubation of the cells with the fluorescently-labeled target molecule. No elution step is required, ruling out some of the complications seen with phage library screening including clonal differences in panning efficiency, nonspecific binding to the support material and inabil- 
ity to elute the very tightly binding clones ${ }^{57,58}$. In addition, growth rate differences due to relative host tolerance of various sequences ${ }^{59}$ may be controlled by using inducible expression systems or limiting clonal competition after induction and selection ${ }^{60}$. Because binding takes place in solution, multiple-point attachment leading to avidity effects ${ }^{47,48,61}$, is eliminated (Fig. 1).

In the screening of CSDLs by FACS, the fluorescence intensity of cells expressing surface exposed proteins depends on the intrinsic affinity, the expression level, and the cell size. Differences in cell size can be taken into account by setting the appropriate forward scattering gate during the selection, a standard procedure in flow cytometry. The fact that high intensity clones may arise because of more efficient expression, rather than higher affinity for the target, is often an advantage since, ultimately, the selected ligands will have to be produced on a large scale and expression level is usually a major limitation ${ }^{55,61}$. Nevertheless, expression level differences can be taken into account by using two-color FACS ${ }^{40}$. Here, the cells are simply labeled by a second fluorescent probe having a different emission wavelength (usually a labeled monoclonal antibody) that recognizes a constant, nonmutated part of the displayed polypeptide. The fluorescent intensity of the second probe is used to normalize the signal due to ligand binding.

An additional advantage of FACS instrumentation for library screening is the quantitative information provided prior to, and during, library screening. Our laboratory has shown that the mean fluorescence intensity of cells displaying scFv mutants varies exactly as expected on the basis of the antigen affinity of the corresponding $s c F v$ antibodies in solution ${ }^{60}$. Moreover, the apparent affinity of the surface-displayed protein for the target can be determined directly by flow cytometry, or by radio immunoassay using Scatchard analysis $^{62}$. The equilibrium dissociation constant $\left(\mathrm{K}_{\mathrm{d}}\right)$ values obtained in this manner agree well with those from measurements made with the purified protein in soluble form (unpublished data).

Following the initial construction of a CSDL, subsequent steps in library handling are straightforward. Libraries are propagated by growing the cells in liquid cultures; selected clones are purified and amplified in one step by plating on agar. Microbial cells have the advantage over phage particles of not being airborne, thus reducing the risk for library cross-contamination. On the other hand, CSDLs have two limitations. First, cell surfaces are much more complex than those of bacteriophages. At present, it is not known whether the proximity of the polypeptide ligand to surface molecules could interfere with binding. The second limitation is due to library size. For microorganisms other than $E$. coli, the library size is limited by the transformation efficiency and realistically, it cannot be much larger than $10^{5}$ clones. Transformation efficiency is less of a problem with $E$. coli but ultimately, the sorting speed attainable in flow cytometers may be limiting. Currently, commercial cell sorters operate at throughput speeds as high as $4 \times 10^{7}$ cells per hour. While the size of libraries that can be realistically screened using such instrumentation should be adequate for most applications, there are circumstances where much larger libraries generated using phage have to be used ${ }^{63}$. The throughput limitations of CSDLs may be circumvented by using iterative or recursive screening techniques involving a series of mutagenesis and selection steps $s^{49,64}$. In addition, advances in flow sorting technologies are continuously pushing the practical limits of CSDL screening. With current state of the art FACS instrumentation the maximum throughput rate is $3.6 \times 10^{8}$ cells $/ \mathrm{hr}^{65}$.

Live recombinant bacterial vaccines. Live recombinant vaccines consist of an avirulent bacterial or viral carrier expressing heterologous antigens. Bacteria are attractive candidates as carriers of foreign antigens in live recombinant vaccines because they are often strongly immunogenic and capable of colonizing host tissues. Viruses are generally more appropriate as carriers when the

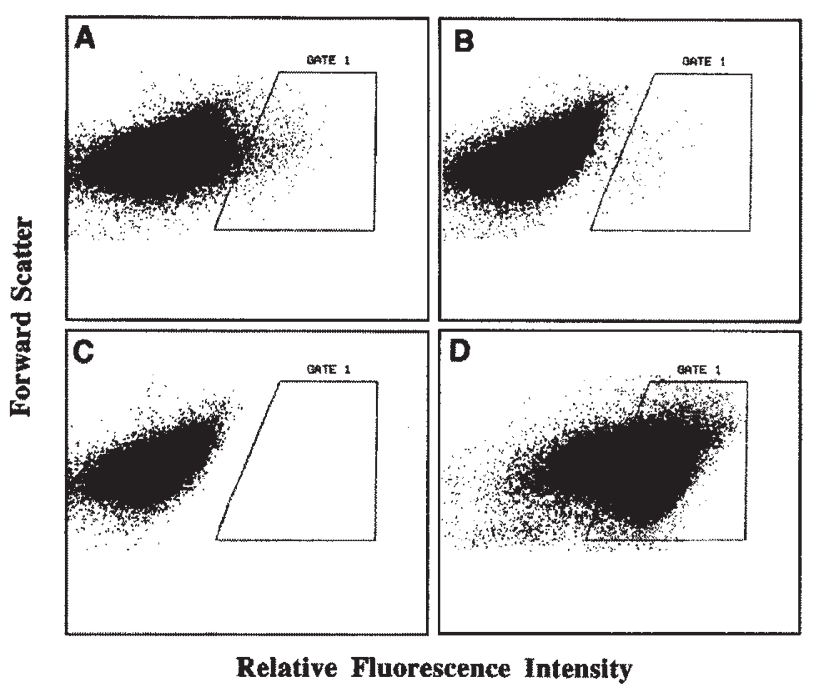

Figure 1. An example of a library selection experiment to select directly for high affinity ScFv expressing cells by using limiting concentrations of fluorescently-conjugated antigen. Three antigencontact residues of an anti-digoxin scFv: TrpH:100, MetH:100b, and SerH:95 were randomized by overlap PCR. The resulting library was transformed into $E$. coli JM109 and analyzed by flow cytometry after incubation with fluorescein-digoxøin at (A) $10^{-7} \mathrm{M}$ (B) $10^{-8} \mathrm{M}$ (C) $O \mathrm{M}$. (D) Example of a positive clone which was isolated from the library by FACS.

heterologous antigen must be postranslationally modified for proper presentation to the immune system. Moreover, bacterial vaccines, unlike viral vaccines, have the ability to express several different foreign antigens and in different forms (e.g., soluble, membrane bound, secreted). Foreign antigen localization, expression level, stability, and modulation of immune responses are key parameters in the development of live recombinant bacterial vaccines ${ }^{11,66,67}$.

Presentation of antigens on the surface of bacteria is a particularly attractive approach to vaccine design for a number of reasons: (1) a variety of expression systems for surface display of proteins and peptides is now available, (2) polypeptide antigens exposed on the outside surface of the cell may be more easily recognized by the immune system, and (3) bacterial outer membrane proteins, lipopolysaccharides (LPS), and secreted toxins are strongly immunogenic and have been exploited to develop a number of nonrecombinant vaccines. Therefore, cell surface components may mediate an immuno-adjuvant effect to surface displayed heterologous antigens.

A variety of avirulent bacterial strains have been developed for use as nonrecombinant live vaccines or as recombinant vaccine vehicles. Upon immunization by various routes, such bacteria replicate inside the target tissues of the host. The foreign antigens are expressed in vivo and thereby are presented to the host immune system. Bacteria used as recombinant vaccine vehicles include: Salmonellae, Vibrio cholerae, Mycobacterium bovis, Streptococcus gordonii, E. coli, Shigella, Lactobacillus, Listeria monocytogenes, and Bacillus subtilis. Several articles describing the above bacterial vectors and their applications in vaccine development have been published ${ }^{67-72}$. We discuss only examples of live bacterial vaccines engineered for surface presentation of foreign antigens.

Salmonella is genetically one of the best characterized organisms used as a recombinant bacterial vaccine vector. Salmonella strains with mutations in genes such as aro $A, c y a, c r p$, aro $C, o m p R$, and $p h o P / p h o Q$ are avirulent but retain immunogenicity ${ }^{67,69}$. Secretory antibody immune responses against foreign antigens expressed by recombinant Salmonella vaccines have been reported ${ }^{68}$. Several laboratories have constructed recombinant Salmonella 
strains that express outer membrane-associated antigens from Gram-negative pathogens. Such outer membrane-associated antigens are often capable of correct localization in the heterologous Salmonella host and become displayed on the surface. Expression of heterologous $\mathrm{O}$ antigens in Gram-negative bacteria generally results in a strong antibody response and therefore is a promising approach for live bacterial vaccine development ${ }^{46}$. Formal and coworkers were the first to use an avirulent Salmonella strain as a vector for the display of heterologous antigen $\mathrm{s}^{73}$. They expressed the $\mathrm{O}$ antigen of the Shigella sonnei lipopolysaccharide on the cell surface of the oral vaccine strain S. typhi Ty21a. Animal studies demonstrated that mice immunized with the recombinant bacteria were protected against challenge with both virulent $S$. typhi and $S$. sonnei and that immunized rabbits produced agglutinating antibodies against the foreign antigen. This vaccine was shown to be safe when human volunteers were immunized orally with the recombinant bacteria ${ }^{74}$. In other studies a $S$. typhimurium galE mutant was transformed with a plasmid containing the genes for the pili proteins $\mathrm{K} 88$ of an enterotoxigenic E. coli strain ${ }^{75}$. Oral immunization of mice with the recombinant Salmonella vaccine resulted in high titers of serum and mucosal antibodies specific against $\mathrm{K} 88$ antigens. Recently, it was shown that oral vaccination with an attenuated S. typhimurium aroA strain expressing outer membrane protein OspA of Borrelia burgodorferi on the cell surface prevents murine lyme borreliosis ${ }^{76}$.

In addition to antigens that are localized on the Salmonella surface without the need for a carrier protein, expression systems employing fusions to outer membrane proteins such as OmpA, LamB, PhoE, and the IgA protease B subunit have been used to direct the surface display of foreign epitopes. Mice immunized orally and intraperitoneally with a $S$. typhimurium aroA strain expressing LamB-Shiga toxin B subunit hybrids developed specific mucosal and humoral antibody responses?. When an epitope from cholera toxin B subunit was inserted into a flagellin vector, it was found that systemic intraperitoneal immunization with the recombinant Salmonella bacteria could evoke antibodies to cholera toxin $^{77}$. E. coli OmpA-malaria HRPII or SERP hybrid proteins could be displayed on the surface of an oral S. typhimurium vaccine vehicle and were capable of inducing specific humoral immune response in mice $^{78}$. Nevertheless, it is not yet clear whether heterologous antigens displayed on the bacterial surface are presented to the immune system by live bacteria or by killed bacteria after the cells have been lysed and partially degraded by host phagocytotic cells. In addition, masking by LPS O-antigen in smooth vaccine strains might prevent the heterologous antigens from being easily recognized by the immune system. In a recent study, it was shown that proteins of Listeria monocytogenes secreted from Salmonella using a hemolysin A derived vector have greater protective efficacy than intracellularly expressed antigen $\mathrm{s}^{79}$. Although in this case the heterologous antigens were localized in the extracellular medium, these results lend support to the hypothesis that extracellularly accessible antigens are better recognized by the immune system than antigens localized in the interior of the bacterial cell.

Certain strains of $E$. coli that are avirulent and nontoxic have been used as carriers for live vaccines. Outer membrane proteins OmpA, PhoE, and LamB are the most commonly used expression vectors in vaccine studies with surface engineered $E$. coli ${ }^{80-83}$. Foreign epitopes from the pre-S2 region of hepatitis B virus surface antigen fused to outer membrane protein $\mathrm{LamB}$ have been stably expressed and exported to the E. coli surface. Intravenous immunization into rabbits and mice resulted in high titer specific antibody responses ${ }^{62}$. The immune response against the inserted peptide was found to parallel the responses against the carrier protein LamB, indicating that antigens may be delivered better to the immune system by using the appropriate protein carriers ${ }^{83}$. Consistent with this conclusion, guinea pigs immunized with partially purified PhoE carrying inserted epitopes from foot-andmouth disease virus gave high levels of neutralizing antibodies

Table 1. Expression systems for protein display in $E$. coli.

\begin{tabular}{|c|c|c|c|c|c|}
\hline Carrier & $\begin{array}{l}\text { Type of } \\
\text { fusion }\end{array}$ & $\begin{array}{l}\text { Localization } \\
\text { of passenger }\end{array}$ & $\begin{array}{l}\text { Passenger } \\
\text { polypeptides }\end{array}$ & Applications & References \\
\hline $\begin{array}{l}\text { Outer membrane proteins } \\
E . \text { coli LamB }\end{array}$ & sandwich fusion & cell surface & $\begin{array}{l}\text { variety of viral } \\
\text { peptide antigens }\end{array}$ & $\begin{array}{l}\text { vaccines, peptide libraries, } \\
\text { cellular adsorbents }\end{array}$ & $4,5,10,12,82,83$ \\
\hline E. coli PhoE & sandwich fusion & cell surface & $\begin{array}{l}\text { epitope from hsp65 } \\
\text { of } M \text {. tuberculosis }\end{array}$ & vaccines & $6,80,84$ \\
\hline Pseudomonas OprF & sandwich fusion & cell surface & $\begin{array}{l}\text { 4-aa epitope from } \\
\text { malaria parasite }\end{array}$ & vaccines & 8 \\
\hline $\begin{array}{l}\text { E. coli or other Gram- } \\
\text { negative lipoproteins }\end{array}$ & $\begin{array}{l}\text { C-terminal or } \\
\text { sandwich fusions }\end{array}$ & $\begin{array}{l}\text { periplasmic side } \\
\text { of outer membrane/ } \\
\text { cell surface }\end{array}$ & $\begin{array}{l}\text { scFv antibodies; } 11 \text {-aa } \\
\text { CE epitope of polio virus }\end{array}$ & $\begin{array}{l}\text { lipid-tagged } \\
\text { antibodies, vaccines }\end{array}$ & $21-23$ \\
\hline E. coll Lpp-OmpA & C-terminal fusion & cell surface & $\begin{array}{l}\text { ScFv antibodies; } \\
\text { B-lactamase; protein A; } \\
\text { cellulose binding proteins }\end{array}$ & $\begin{array}{l}\text { peptide/antibody libraries, } \\
\text { cellular adsorbents, } \\
\text { immunoassays }\end{array}$ & $24,41,56,62$ \\
\hline Shigella VirG ${ }_{3}$ & $\mathrm{~N}$-terminal fusion & cell surface & alkaline phosphatase & unknown & 28 \\
\hline Neisseria $\lg A_{B}$ & $\mathrm{~N}$-terminal fusion & cell surface & cholera toxin B subunit & vaccines, peptide libraries & 31 \\
\hline $\begin{array}{l}\text { Subunits of surface appeno } \\
\text { E. coli Flagellin (FliC) }\end{array}$ & $\begin{array}{l}\text { dages } \\
\text { sandwich fusion }\end{array}$ & cell surface & $\begin{array}{l}\text { thioredoxin; peptides } \\
\text { inserted within thioredoxin }\end{array}$ & peptide libraries & 13 \\
\hline Salmonella Flagellin (FliC) & sandwich fusion & cell surface & $\begin{array}{l}\text { 18-aa epitope from } \\
\text { HIV1 gp41 protein }\end{array}$ & vaccines & 16 \\
\hline E. coli FimH (Type I pili) & sandwich fusion & cell surface & $\begin{array}{l}52-\text { aa sequence from the } \\
\text { preS2 hepatitis } B \text { antigen }\end{array}$ & vaccines & 17 \\
\hline E. coli PapA (Pap pili) & sandwich fusion & cell surface & $\begin{array}{l}\text { 58-aa domain from } \\
\text { Staphylococcus protein A }\end{array}$ & cellular adsorbents & 15 \\
\hline $\begin{array}{l}\text { Secreted proteins } \\
\text { Klebsiella PulA }\end{array}$ & C-terminal fusion & $\begin{array}{l}\text { cell surface/ } \\
\text { extracellular fluid }\end{array}$ & B-lactamase & unknown & 32 \\
\hline
\end{tabular}


and were completely protected against challenge with the virus ${ }^{84}$.

Engineered Gram-positive microorganisms expressing surface displayed foreign antigens can also be used as vectors to develop recombinant vaccines ${ }^{33}$. Streptococcus gordonii, a human oral commensal bacterium can effectively deliver foreign antigens into the oral, respiratory, intestinal, and systemic sites. A gene fusion system based on the C-terminal region of the fibrillar M6 protein from Streptococcus pyogenes has been used to display a 204-a.a. allergen of the white-face hornet venom on the surface of $S$. gordonii. A systemic IgG response together with mucosal IgA responses in different secretions were induced against the foreign surface molecule, after oral immunization with recombinant bacteri ${ }^{33,36,85}$.

There are several other bacterial systems developed and used as vectors for surface exposed antigens including Shigella flexneri and Bordetella pertussis ${ }^{86,87}$. Eukaryotic cells have also been tested as potential carriers of heterologous antigens in live vaccines. For example, Saccharomyces cerevisiae has been used to express a Hepatitis B virus surface antigen on its surface. However, intraperitoneal immunization of animals with the surface-engineered yeast cells resulted in a weak immune response against the foreign antigen ${ }^{38}$. Yeast cells are safe for oral use and cannot be rendered pathogenic by reverse mutations. In addition, certain heterologous antigens can be expressed better in native form in eukaryotic cells than in bacteria. However, yeast cells do not invade, multiply, and survive in the lymphoid tissues and thus cannot serve as a factory to produce the foreign antigen. This causes a need for multiple oral immunizations and an increase of the dose, which makes yeast-based live vaccines expensive and impractical. For these reasons, eukaryotic vectors like yeast do not appear to represent a promising alternative to bacterial or viral vectors for the development of live oral vaccines.

Cell adsorbents and other applications. In addition to the development of library screening and recombinant live vaccines, the display of proteins on bacterial cells is opening up a range of other interesting applications. From a practical standpoint, one can think of microbial cells that display recombinant proteins as microscopic, self-regenerating, immobilized protein matrices. Consequently, they may be used in lieu of immobilized proteins in many applications.

Staphylococcus cells expressing Protein A have been used for many years for the affinity separation of $\operatorname{IgG}^{88-89}$. Other examples under development include the generation of cells expressing metal chelating peptides for the removal of heavy metals and for other bioremediation applications, production of cellular adsorbents for in situ product removal, whole cell adsorbents for protein purifications and others ${ }^{12,88}$. Along the same lines, cells expressing surface immobilized antibodies can substitute for conventional solid phase immunoreagents in analytical applications ${ }^{62}$.

The display of heterologous proteins, particularly when the expression level is significant, has generally been observed to perturb the stability of the cell surface and is often accompanied by the slow leakage of cellular macromolecules. This of course is particularly undesirable when the cells are used as whole cell adsorbents. Fortunately, a simple chemical treatment is sufficient to completely eliminate leakage problems and stabilize the cells for practical applications ${ }^{90}$. Chemically stabilized cells can then be irreversibly adsorbed on treated chitosan particles to prepare a powder-like material that is inexpensive, easy to handle, and suitable for practical applications.

Clearly, the range of applications exploiting the display of proteins on the surface of microorganisms is quite remarkable, especially since suitable expression systems became available only within the last five years. CSDLs, recombinant bacterial vaccines and whole cell adsorbents are expected to find increasingly wider use as expression systems are improved and technical hurdles are overcome. Extrapolating from the rapid rate of progress so far, it is safe to predict that within the next five years technologies based on the display of proteins on the surface of microorganisms will be one of the mainstays in biotechnology and in bioprocessing research and development.

\section{Acknowledgments}

Work in George Georgiou's laboratory in the area of protein display was supported by grants from The Whitaker Foundation and The National Science Foundation. We would like to thank Dane K. Wittrop and Philip Klebba for communicating unpublished results.

1. Whitehorn, E.A., Tate, E., Yanofsky, S.D., Kochersperger, L., Davis, A. Mortensen, R.B., et al. 1995. A generic method for expression and use of "tagged" soluble versions of cell surface receptors. Bio/Technology 13:1215-19.

2. Georgiou, G., Poetschke, H.L., Stathopoulos, C., and Francisco, J.A. 1993. Practical applications of engineering Gram-negative bacterial cell surfaces. Trends Biotechnol. 11:6-10.

3. Little, M., Fuchs, P., Breitling, F., and Dübel, S. 1993. Bacterial surface presentation of proteins and peptides: an alternative to phage technology? Trends Biotechnol. 11:3-5.

4. Hofnung, M. 1991. Expression of foreign polypeptides at the Escherichia coli cell surface. Methods Cell Biol. 34:77-105.

5. Charbit, A., Molla, A., Saurin, W., and Hofnung, M. 1988. Versatility of a vector for expressing foreign polypeptides at the surface of Gram-negative bacteria. Gene 70:181-189.

6. Agterberg, M., Adriaanse, H., van Bruggen, A., Karperien, M., and Tommassen, J. 1990. Outer-membrane PhoE protein of Escherichia coli K-12 as an exposure vector: possibilities and limitations. Gene 88:37-45.

7. Su, G.-F., Brahmbhatt, H.N., Wehland, J., Rohde, M., and Timmis, K.N. 1992 Construction of stable LamB-Shiga toxin B subunit hybrids: analysis of expression in Salmonella typhimurium aro $A$ strains and stimulation of $B$ subunit-specific mucosal and serum antibody responses. Infect. Immun. 60:3345-3359.

8. Wong, R.S.Y., Wirtz, R.A., and Hancock, R.E.W. 1995. Pseudomonas aenuginosa outer membrane protein OprF as an expression vector for foreign epitopes: the effects of positioning and length on the antigenicity of the epitope. Gene 158:55-60.

9. Newton, S.M., Klebba, P.E., Michel, V., Hofnung, M., and Charbit, A. 1996 Topology of the membrane protein LamB by epitope tagging and a comparison with the X-ray model. J. Bacteriol. 178:3447-3456.

10. Brown, S. 1992. Engineered iron oxide-adhesion mutants of the Escherichia coli phage $\lambda$ receptor. Proc. Natl. Acad. Sci. USA 89:8651-8655.

11. O'Callaghan, D., Charbit, A., Martineau, P., Leclerc, C., van der Werf, S., Nauciel, C., and Hofnung, M. 1990. Immunogenicity of foreign peptide epitopes expressed in bacterial envelope proteins. Res. Microbiol. 141:963-969.

12. Sousa, C., Cebolla, A., and de Lorenzo, V. 1996. Enhanced metalloadsorption of bacterial cells displaying poly-His peptides. Nature Biotech. 14:1017-1020.

13. Lu, Z., Murray, K.S., Van Cleave V., LaVallie, E.R., Stahl, M.L., and McCoy, J.M. 1995. Expression of thioredoxin random peptide libraries on the Escherichia coli cell surface as functional fusions to flagellin: A system designed for exploring protein-protein interactions. Bio/Technology 13:366-372.

14. Colas, P., Cohen, B., Jessen, T., Grishina, I., McCoy, J., and Brent, R. 1996 Genetic selection of peptide aptamers that recognize cyclin-dependent kinase 2. Nature 380:548-550.

15. Steidler, L., Remaut, E., and Fiers, W. 1993. Pap pili as a vector system for surface for surface exposition of an immunoglobulin G-binding domain of protein A of Staphylococcus aureus in Escherichia coli. J. Bacteriol. 175:7639-7643.

16. Newton, S.M.C., Joys, T.M., Anderson, S.A., Kennedy, R.C., Hovi, M.E., and Stocker, B.A.D. 1995. Expression and immunogenicity of an 18-residue epitope of HIV1 gp41 inserted in the flagellar protein of a Salmonella live vaccine. Res. Microbiol. 146:203-216.

17. Pallesen, L., Poulsen, L.K., Christiansen, G., and Klemm, P. 1995. Chimeric FimH adhesin of type 1 fimbriae: a bacterial surface display system for heterologous sequences. Microbiology 141:2839-2848.

18. van Die, I., van Osterhout, J., van Megen, I., Bergmans, H., Hoekstra, W., EngerValk, B., et al. 1990. Expression of foreign epitopes in P-fimbriae of Escherichia coli. Mol. Gen. Genet. 222:297-303.

19. Salmong, G.P.C. and Reeves, P.J. 1993. Membrane traffic wardens and protein secretion in Gram-negative bacteria. Trends Biol. Sci. 18:7-12.

20. Taylor, I.M., Harrison, J.L., Timmis, K.N., and O'Connor, C.D. 1990. The TraT lipoprotein as a vehicle for the transport of foreign antigenic determinants to the cell surface of Escherichia coli K12: structure-function relationship in the TraT protein. Mol. Microbiol, 4:1259-1268.

21. Laukkanen, M.-L., Teeri, T.T., and Keinanen, K. 1993. Lipid-tagged antibodies: bacterial expression and characterization of a lipoprotein-single-chain antibody fusion protein. Protein Engineer. 6:449-454

22. Fuchs, P., Breitling, F., Dübel, S., Seehaus, T., and Little, M. 1991. Targeting recombinant antibodies to the surface of Escherichia coli: fusion to a peptidoglycan-associated lipoprotein. Bio/Technology 9:1369-1372.

23. Cornellis, P., Sierra, J.C., Lim Jr., A., Malur, A., Tungpradabkul, S., Tazka, H., et al. 1996. Development of new cloning vectors for the production of immunogenic outer membrane fusion proteins in Escherichia coli. Bio/Technology 14:203-208.

24. Francisco, J.A., Earhart, C.F., and Georgiou, G. 1992. Transport and anchoring of B-lactamase to the external surface of Escherichia coli. Proc. Natl. Acad. Sci. USA 89:2713-2717.

25. Stathopoulos, C., Georgiou, G., and Earhart, C.F. 1996. Characterization of Escherichia coli expressing an Lpp'OmpA(46-159)-PhoA fusion protein localized in the outer membrane. Appl. Microbiol. Biotechnol. 45:112-119. 
26. Klauser, T., Pohlner, J., and Meyer, T.F. 1993. The secretion pathway of IgA protease-type proteins in Gram-negative bacteria. Bioessays 15:799-805

27. Jose, J., Jaehnig, F., and Meyer, T.F. 1995. Common structural features of IgA1 protease-like outer membrane protein. Mol. Microbiol. 18:378-380.

28. Suzuki, T., Leth, M.-C., and Sasakawa, C. 1995. Extracellular transport of VirG protein in Shigella. J. Biol. Chem. 270:30874-30880.

29. Provence, D.L., Stathopoulos, C., and Curtiss, R. Ill. 1997. Analysis of the extracellular secretion of the putative hemagglutinin Tsh of an avian pathogenic Escherichia coli strain: evidence for an autonomous IgA protease-type secretion. In preparation.

30. St. Geme, J.W. III, de la Morena, M.L., and Falkow, S. 1994. A Haemophilus influenzae IgA protease-like protein promotes intimate interaction with human epithelial cells. Mol. Microbiol. 14:217-233.

31. Klauser, T., Pohlner, J., and Meyer, T.F. 1990. Extracellular transport of cholera toxin B subunit using Neisseria IgA protease B-domain: conformation-dependent outer membrane translocation. EMBO J. 9:1991-1999.

32. Kornacker, M.G. and Pugsley, A.P. 1990. The normally periplasmic enzyme Blactamase is specifically and efficiently translocated through the Escherichia coli outer membrane when it is fused to the cell-surface enzyme pullulanase. Mol. Microbiol. 4:1101-1109.

33. Fischetti, V.A. 1996. Gram-positive commensal bacteria deliver antigens to elicit mucosal and systemic immunity. ASM News 62:405-410.

34. Hansson, M., Stahl, S., Nguyen, T.N., Bachi, T., Robert, A., Binz, H., et al. 1992. Expression of recombinant proteins on the surface of the coagulase-negative bacterium Staphylococcus xylosus. J. Bacteriol. 174:4239-4245.

35. Samuelson, P., Hansson, M., Ahlborg, N., Andreoni, C., Gotz, F., Bachi, T., et al. 1995. Cell surface display of recombinant proteins on Staphylococcus carnosus. J. Bacteriol. 177:1470-1476.

36. Pozzi, G., Contorni, M., Oggioni, M.R., Manganelli, R., Tommasino, M., Cavalieri, F., and Fischetti, V.A. 1992. Delivery and expression of a heterologous antigen on the surface of streptococci. Infect. Immun. 60:1902-1907.

37. Schreuder, M.P., Brekelmans, S., van der Ende, H., and Klis, F.M. 1993. Targeting of a heterologous protein to the cell wall of Saccharomyces cerevisiae. Yeast 9:399-409.

38. Schreuder, M.P., Deen, C., Boersma, W.J.A., Pouwels, P.H., and Klis, F.M. 1996. Yeast expressing hepatitis $B$ virus surface antigen determinants on its surface: implications for a possible oral vaccine. Vaccine 14:383-388.

39. Shreuder, M.P., Mooren, A.T.A., Toschka, H.Y., Verrips, C.T., and Klis, F.M. 1996. Immobilizing proteins on the surface of yeast cells. Trends Biotechnol. 14:115-120.

40. Boder, E.T. and Wittrup, K.D. 1996. Surface display of a functional single chain Fv antibody in Saccharomyces cerevisiae. Submitted.

41. Georgiou, G., Stephens, D.L., Stathopoulos, C., Poetschle H.L., Mendenhall, J., and Earhart, C.F. 1996. Display of B-lactamase on the Escherichia coli surface: outer membrane phenotypes conferred by $L \mathrm{pp}^{\prime}-O \mathrm{OPA}^{\prime}-\beta$-lactamase fusions. Protein Engineer. 9:239-247.

42. Messner, P., Mazid, M.A., Unger, F.M., and Sleytr, U.B. 1992. Artificial antigens. Synthetic carbohydrate haptens immobilized on crystailine bacterial surface layer glycoproteins. Carbohydr. Res. 233:175-184.

43. Jahn-Schmid, B., Messner, P., Unger, F.M., Sleytr, U.B., Scheiner, O., Kraft, D. 1996. Toward selective elicitation of TH1-controlled vaccination responses: vaccine applications of bacterial surface layer proteins. J. Biotechnol. 44:225-231.

44. Goldberg, J.B., Hatano, K., Meluleni, G.M., and Pier, G.B. 1992. Cloning and surface expression of Pseudomonas aeruginosa $\mathrm{O}$ antigen in Escherichia coli. Proc. Natl. Acad. Sci. USA 89:10716-10720.

45. Scott, J.K. and Smith, G.P. 1990. Searching for peptide ligands with an epitope library. Science 249:386-390.

46. Hill, R.H. and Stockey, P.G. 1996. Phage presentation. Mol. Microbiol. 20:685-692.

47. Lowman, H.B. and Wells, J.A. 1993. Affinity maturation of human growth hormone by monovalent phage display. J. Mol. Biol. 234:564-578.

48. Bonnycastle, L.L.C., Mehroke, J.S., Rashed, M., Gong, X., and Scott, J.K. 1996. Probing the basis of antibody reactivity with a panel of constrained peptide libraries displayed by filamentous phage. J. Mol. Biol. 258:747-762.

49. Markland, W., Ley, A.C., Lee, S.W., and Ladner, R.C. 1996. Iterative optimization of high affinity protease inhibitors using phage display. 1 plasmin. Biochem. 35:8045-8057.

50. Wang, C.I., Yang. Q., and Craik, C.S. 1996. Phage display of proteases and macromolecular inhibitors. Methods Enzymol. 267:28-51.

51. Matthews, D.J. and Wells, J.A. 1993. Substrate phage: Selection of protease substrates by monovalent phage display. Science 260:113-117.

52. Choo, Y. and Klug, A. 1994. Toward a code for the interactions of zinc fingers with DNA: Selection of randomized zinc fingers displayed on phage. Proc. Natl. Acad. Sci. USA 91:11163-11167.

53. Burton, D.R. and Barbas III, C.F. 1994. Human antibodies from combinatorial libraries. Adv. Immunol. 57:191-281.

54. Harrison, J.L., Williams, S.C., Winter, G., and Nissim, A. 1996. Screening of phage antibody libraries. Meth. Enzymol. 267:109-115.

55. Tang, Y., Jiang, N., Prakh, C., and Hilvert, D. 1996. Selection of linkers for a catalytic single chain antibody using phage display technology. J. Biol. Chem. 271:15682-15686.

56. Francisco, J.A., Campbell, R., Iverson, B.L., and Georgiou, G. 1993. Production and fluorescence-activated cell sorting of Escherichia coli expressing a functional antibody fragment on the external surface. Proc. Natl. Acad. Sci. USA 90:10444-10448.

57. Adey, N.B., Mataragnon, A.H., Rider, J.E., Carter, J.M., and Kay, B.K. 1995. Characterization of phage that binds plastic from phage-displayed random peptide libraries. Gene 156:27-31.

58. Short, M.K. Jeffrey, P.D., Kwong, R., and Margolies, M.N. 1995. Contribution of antibody heavy chain CDR1 to digoxin binding analyzed by random mutagenesis of phage-displayed Fab 26-10. J. Biol. Chem. 270:28541-28550.

59. Knappik, A. and Plückthun, A. 1995. Engineered turns of a recombinant antibody improve its in vivo folding. Protein Eng. 8:81-89.
60. Daugherty, P., Chen, G., Iverson, B.L., and Georgiou, G. 1997. Isolation of high affinity antibodies from libraries displayed on the surface of bacteria. in preparation.

61. Crameri, A., Cwirla, S., and Stemmer, W.P.C. 1996. Construction and evolution of antibody-phage libraries by DNA shuffling. Nature Medic. 2:100-102.

62. Chen, G., Cloud, J., Georgiou, G., and Iverson, B.L. 1996. A quantitative immunoassay utijzing Escherichia coll cells possessing surface-exposed single chain $\mathrm{Fv}$ molecules. Biotechnol. Progr. 12:572-574.

63. Griffiths, D. et al. 1993. Human anti-self antibodies with high specificity from phage display libraries. EMBO J. 12:725-734

64. Yang, W.-P., Green, K., Pinz-Sweeney, S., Briones, A.T., Burton, D.R., and Barbas III, C.F. 1996. CDR walking mutagenesis for the affinity maturation of a potent human anti-HIV antibody into the picomolar range. J. Mol. Biol. 254:392-403.

65. Leary, J.F., McLaughlin, S.R., and Kavanau, K. 1995. New methods for detection, analysis and isolation of rare cell populations. SPIE 2678:240-253.

66. Curtiss, R. Ill. 1990. Antigen delivery systems for analysing host immune responses and for vaccine development. Trends Biotechnol. 8:237-240.

67. Roberts, M., Chatfield, S.N., Dougan, G. 1994. Salmonella as carriers of heterologous antigens, pp. 27-58 in Novel delivery systems for oral vaccines. O'Hagan, D.T. (ed.). CRC Press, Inc.

68. Curtiss, R. III. 1990. Attenuated Salmonella strains as live vectors for the expression of foreign antigens, pp. 161-188 in New generation vaccines. Woodrow, G.C. and Levine, M.M. (eds.). Marcel Dekker, Inc.

69. Gardenas, L. and Clements, J.D. 1992. Oral immunization using live attenuated Salmonella spp. as carriers of foreign antigens. Clin. Microbiol. Rev, 5:328-342.

70. Cirillo, J.D., Stover, C.K., Bloom, B.R., Jacobs, W.R., Jr., Barletta, R.G. 1995. Bacterial vaccine vectors and Bacilsus Cafmette-Guerin. Clin. Infect. Dis. 20:1001-1009.

71. Fortaine, A., Arondel, J., and Sansonetti, P.J. 1990. Construction and evaluation of live attenuated vaccine strains of Shigella flexneri and Shigella dysenteriae 1. Res. Microbiol. 141:907-912.

72. Curtiss, R. III, Doggett, T., Nayak, A.R., and Srinivason, J. 1996. Strategies for the use of live recombinant avirulent bacterial vaccines for mucosal immunization, pp. 499-511 in Essentials of mucosal immunology. Kagnoff, M.F. and Kiyono, H. (eds.). Acadernic Press, Inc.

73. Formal, S.B., Baron, L.S., Kopecko, D.J., Powell, C, and Life, C.A. 1981 Construction of a potent bivalent vaccine strain: introduction of Shigella sonnei form I antigen genes into the galE S. typhi Ty21a typhoid vaccine strain. Infect. Immun. 34:746-750.

74. van de Verg, L., Herrington, D.A., Murphy, J.R. Wasserman, S.S., Formal, S.B., and Levine, M.M. 1990. Specific immunoglobulin A-secreting cells in peripheral blood of humans following oral immunization with a bivalent Salmonella typhi-Shigella sonnei vaccine or infection by pathogenic S. sonnei. Infect. Immun. 58:2002-2004

75. Stevenson, G. and Manning, P.A. 1985. Galactose epimeraseless (galE) mutant G30 of Salmonella typhimurium is a good potential tive oral vaccine carrier for fimbrial antigens. FEMS Microbiol. Lett. 28:317-321.

76. Dunn, M., Al-Ramadi, B.K., Barthold, S.-W., Flavell, R.A., and Fikrig, E. 1995. Oral vaccination with an attenuated Salmonella typhimurium strain expressing Borrelia burgdorferi OspA prevents murine Lyme Borreliosis. Infect. Immun. 63:1611-1614.

77. Newton, S.M., Jacob, C., and Stocker, B.A.D. 1989. Immune responses to cholera toxin epitope inserted in Salmonella flagellin. Science 244:70-72.

78. Schorr, J., Knapp, B., Hundt, E., Küpper, H.A., and Amrnan, E. 1991. Surface expression of malarial antigens in Salmonella typhimurium: induction of serum antibody response upon oral vaccination of mice. Vaccine 9:675-681.

79. Hess, J., Gentschev, I., Miko, D., Welzel, M., Ladel, C., Goebel, W., and Kaufmann S.H.E. 1996. Superior efficacy of secreted over somatic antigen display in recombinant Salmonella vaccine induced protection against listeriosis. Proc. Natl. Acad. Sci. USA 93:1458-1463.

80. Janssen, R., Wauben, M., Zee, R., Tommassen, J. 1994. Immunogenicity of a mycobacterial T-cell epitope expressed in outer membrane protein PhoE of E. coli. Vaccine 12:406-409.

81. Ruppert, A., Arnold, N., and Hobom, G. 1994. OmpA-FMDV VP1 fusion protein production, cell surface exposure and immune responses to the major antigenic domain of foot-and-mouth disease virus. Vaccine 12:492-498.

82. Charbit, A., Sobczak, E., Michel, M-L, Molla, A., Tiollais, P. and Hofnung, M. 1987. Presentation of two epitopes of the preS2 region of hepatitis $B$ virus on live recombinant bacteria. J. Immunol. 139:1644-1658.

83. Leclerc, C., Charbit, A., Molla, A., and Hofnung, M. 1989. Antibody response to a foreign epitope expressed at the surface of recombinant bacteria: importance of the route of immunization. Vaccine 7:242-248.

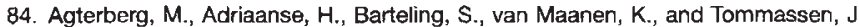
1990. Protection of guinea-pigs against foot-and-mouth disease virus by immunization with a PhoE-FMDV hybrid protein. Vaccine $8: 438-440$

85. Medaglini, D., Pozzi, G., King, T.P., and Fischetti, V.A. 1995. Mucosal and systemic immune responses to a recombinant protein expressed on the surface of the oral commensal bacterium Streptococcus gordonii after oral colonization. Proc. Natl. Acad. Sci. USA 92:6868-6872

86. Ryd, M., Verma, N., and Lindberg, A.A. 1992. Induction of a humoral immune response to a Shiga toxin B subunit epitope expressed as a chimeric LamB protein in a Shigella flexneri live vaccine strain. Microbiol. Pathogen. 12:399-407.

87. Renauld-Mongenie, G., Mielcarek, N., Cornette, J., Schacht, A.-M., Capron, A., Riveau, G., and Locht, C. 1996. Induction of mucosal immune responses against a heterologous antigen fused to a filamentous hemagglutinin after intranasa immunization with recombinant Bordetella petrussis. Proc. Natl. Acad. Sci. USA 93:7944-7949.

88. Goding, J.W. 1978. Use of Staphylococcal protein A as an immunological reagent. J. Immunol. Meth. 20:241-254.

89. Rantamaki, L.K. and Muller, H.-P. 1995. Purification of goat immunoglobulin G1 (lgG1) and lgG2 antibodies by use of Streptococcus dysgalactiae cells with Fc receptors. Veter immunol. immunopath, 45:115-126.

90. Freeman, A., Abramov, S., and Georgiou, G. 1996. Fixation and stabilization of $E$. coli cells displaying genetically engineered cell surface proteins. Biotechnol. Bioeng. 52:625-630. 